\title{
ERRATUM
}

\section{Erratum zu: Was ist eine ökologische Schadensschwelle?}

\author{
Horst-Henning Steinmann ${ }^{1} \cdot$ Friederike de $\mathrm{Mol}^{2}$ • Joachim Kakau³ - Bärbel Gerowitt ${ }^{2}$
}

Online publiziert: 19. Juli 2021

(c) Der/die Autor(en) 2021

\section{Erratum zu:}

\section{Gesunde Pflanzen 2021}

https://doi.org/10.1007/s10343-021-00551-9

Im Kapitel „Entwicklung eines theoretischen Rahmens für ökologische Schadensschwellen" wurde die Einbeziehung von Ökosystemleistungen in die ökonomischen Berechnungen diskutiert. Dabei ist im Textabschnitt „Beispiele“ auf S. 144 versehentlich fehlerhaft fünfmal die x-Achse angesprochen worden. Richtig ist, dass in den Abb. 3, 4, 5, 6 und 7 die Systemleistungen auf der y-Achse abgebildet sind.
Funding Open Access funding enabled and organized by Projekt DEAL.

Open Access Dieser Artikel wird unter der Creative Commons Namensnennung 4.0 International Lizenz veröffentlicht, welche die Nutzung, Vervielfältigung, Bearbeitung, Verbreitung und Wiedergabe in jeglichem Medium und Format erlaubt, sofern Sie den/die ursprünglichen Autor(en) und die Quelle ordnungsgemäß nennen, einen Link zur Creative Commons Lizenz beifügen und angeben, ob Änderungen vorgenommen wurden.

Die in diesem Artikel enthaltenen Bilder und sonstiges Drittmaterial unterliegen ebenfalls der genannten Creative Commons Lizenz, sofern sich aus der Abbildungslegende nichts anderes ergibt. Sofern das betreffende Material nicht unter der genannten Creative Commons Lizenz steht und die betreffende Handlung nicht nach gesetzlichen Vorschriften erlaubt ist, ist für die oben aufgeführten Weiterverwendungen des Materials die Einwilligung des jeweiligen Rechteinhabers einzuholen.

Weitere Details zur Lizenz entnehmen Sie bitte der Lizenzinformation auf http://creativecommons.org/licenses/by/4.0/deed.de.

Horst-Henning Steinmann ist wissenschaftlicher Koordinator am Zentrum für Biodiversität und nachhaltige Landnutzung an der GeorgAugust-Universität Göttingen. Er beschäftigt sich mit der Analyse und Weiterentwicklung von Ackerbausystemen.

Die Online-Version des Originalartikels ist unter https://doi.org/ 10.1007/s10343-021-00551-9 zu finden.

Horst-Henning Steinmann

hsteinm@gwdg.de

1 Zentrum für Biodiversität und nachhaltige Landnutzung, Georg-August-Universität Göttingen, Göttingen, Deutschland

2 Professur Phytomedizin, Universität Rostock, Rostock, Deutschland

3 Fachgebiet Integrierter Pflanzenschutz, Hochschule Osnabrück, Osnabrück, Deutschland 